\title{
Effect of the nutritional stabilization program 'ESNUT' on body composition, stages of change and self-perception of body image in university students
}

\author{
Jazmín García-Navarro Karen, Josefina Gallegos-Martínez, Jaime Reyes-Hernández \\ Facultad de Enfermería y Nutrición, Universidad Autónoma de San Luis Potosí, México
}

Received: February 16, 2020

Accepted: March 24, 2020

Online Published: March 30, 2020

DOI: $10.5430 /$ jnep.v10n7p18

URL: https://doi.org/10.5430/jnep.v10n7p18

\begin{abstract}
Background and objective: Adolescents have changes in diet when entering university (leaving out and irregularity in mealtimes, low intake of fruits and vegetables and high intake of junk food and sugary drinks), often body self-perception does not match the actual body composition leading young people to unhealthy practices. Nutritional educational interventions have been successful based on the Transtheoretical Model of Change. To assess the effectiveness of the educational intervention for Nutritional Stabilization "ESNUT" (name in Spanish) in body composition, stages of change, body self-perception and the concordance level with BMI of students newly admitted to a university before and in post-intervention follow-ups.

Methods: Quasi-experimental study with control group in students from 17 to 21 years newly admitted to a university who agreed to participate in the study. Independent variable: Educational intervention Nutrition Stabilization Model "ESNUT" and dependent variables: body self-perception, body composition, BMI. Instruments: SECA 274 digital stadiometer, InBody 230 Bioimpedanciometer, body silhouettes test and change assessment scale of the University of Rhode Island (URICA). Analysis. Descriptive statistics, student's $t$ (comparison of means) and Pearson's $\mathrm{r}$ (correlation) with support from the statistical program SPSS version 18 .

Results: About $50 \%$ of the experimental group showed normal nutritional status according to the Real BMI but only $17 \%$ according to the fat mass percentage in the third month of follow-up was 50\%. A discrepancy was observed with the Perceived BMI, $67 \%$ had a self-perception of normal weight. In the experimental precontemplation group, at basal near 50\%, it finally reduced $20 \%$ and placed in preparation/action.

Conclusions: The effectiveness of the "ESNUT" intervention was observed in the experimental group through body composition with a reduction in the percentage of fat mass, therefore Overweight/Obesity. Self-perception of body image in its correlated Perceived Body Mass Index (BMI) versus Real BMI increased their level of concord. The transition from pre-contemplation to contemplation was observed in the stages of change, as well as from this towards preparation/action. The control group made little progress due to relapse to predecessor stages and revealed itself in an increase in the percentage of body fat. Both the experimental and control groups tended to underestimate the perceived BMI versus the actual BMI. Clinical importance: Identifying the stage of change allows feedback in the support of the change and motivates the participants according to the stage in which they are.
\end{abstract}

Key Words: Transtheoretical model, Education, Obesity, Student health

*Correspondence: Josefina Gallegos-Martínez; Email: jgallego@uaslp.mx; Address: Facultad de Enfermería y Nutrición, Universidad Autónoma de San Luis Potosí, Av. Niño Artillero, 130, Zip Code: 78290, San Luis Potosí, S.L.P., México. 


\section{INTRODUCTION}

Adolescence occurs between 10 and 19 years of age, his age range falls within WHO's definition of young people (individuals 10 and 24 years of age). ${ }^{[1]}$ For 2019, this corresponds to $17.9 \%$ of the population in Mexico and $19.5 \%$ in San Luis Potosí according to the Institute of Statistics and Geography (INEGI). ${ }^{[2]}$ Towards the end of this stage the adolescent enrolls in the university and this produces social, economic, cultural and psychological changes, which result in a modified nutritional diet principally low in the consumption of fruits and vegetables, excessive consumption of sugar drinks and fast foods. Not establishing proper times for eating or not eating at all leads to malnutrition, a deficiency or excess of nutrients, loss of weight, obesity, insulin resistance, dyslipidemia, hypertension, amongst other alterations. ${ }^{[3-6]}$ Other factors that influence eating habits among adolescents and young adults is the self-perception of their body image (SPBI). The SPBI is related to the restrictive diets and/or intense exercise due to the image perceived or desired which does not coincide with their true body image. Generally, adolescents do not obtain a positive SPBI and for this reason it has been attributed to various personal and psychological disorders. It has been demonstrated a proportionate dissatisfaction between the SPBI and body mass index (BMI). ${ }^{[7,8]}$ The Latin population is three times less in agreement as to the relationship of real weight and SPBI. ${ }^{[9]}$

The Nutritional Stabilization model (ESNUT) is an educational initiative aimed at instilling the knowledge and attitude for choosing a nutritious diet which implies electing the right foods and activities of individuals for eating healthy. In this sense, the Transtheoretical Model of Change (TMC) based on health psychology has been applied by health professionals on interventions to create changes for healthier attitudes. The TMC has been applied to groups in order to achieve healthier activities and diets. The stages for change start with a preconcepted notion (there is no intention of changing one's attitude in the near future), in this concept it is openly expressed the intention for change, and where there is intent, the preparation continues to do something, and where there is the intent in respect to attitudes, actions take place when attitudes are modified. ${ }^{[7-10]}$

As previously mentioned, at the university level is when nutrition is at risk and adolescents should receive nutritional instruction to promote good eating habits, especially at this time when they start to select their own eating preferences.

\section{MeTHODS}

\subsection{Design}

Study of prospective intervention (three months postintervention) with experimental group (EG) and control group (CG), by simple blind random assignment. Place of study. University Health Center (UHC) and Faculty of Science (FC) of the Universidad Autónoma de San Luis Potosí (UASLP).

\subsection{Sample and sampling}

Recruitment was undertaken by invitation of 120 freshmen students of the Sciences Faculty and at the UHC that attended for services during different days of the week. The students had schedule limitations due to academic load, which is why the majority declined the invitation to participate in the study. A brief explanation was given and then the volunteers where explained in detail their participation at location provided for the study. A drawing was conducted for assignment to the EG or CG. The sampling was concluded when the students met the criteria for selection between 17 and 21 years, healthy, not athletic and by written consent.

\subsection{Basal equivalency of groups}

The EG and CG had an equivalency $(p \geq .05)$ a proportionate distribution per sex $(\mathrm{EG} \mathrm{s}=12)$ females $7(58 \%)$ and male 5 (42\%); CG (s = 27) females $12(44 \%)$ and male $15(56 \%)$, also in BMI real (EG $24.7 \pm 3.2$; CG $25.8 \pm 3.9$ ), weight (EG $66.4 \pm 12.2$; CG $72.6 \pm 16.0 \mathrm{Kg}$ ) and change stages (precontemplation EG 5 (42\%); CG 7 (26\%); contemplation EG 7 (58\%); CG 17 (63\%) and preparation/action EG (0); CG $3(11 \%)$. They were basally different $(p \leq .001)$ per age (EG 18.3 $\pm 0.98 ;$ CG $19.5 \pm 1.1$ years) and the percentage of grease (EG $32.6 \pm 5.2 ; \mathrm{CG} 22.6 \pm 10.4)$.

\subsection{Variables}

\subsubsection{Educational Intervention Nutritional Stabilization} Model

"ESNUT" adapted for youngsters ${ }^{[12,13]}$ and modeled as a group course-lab study with a duration of 8 hours (see Table $1)$.

\subsubsection{Dependent variables and instruments}

Body image self-perception with its Perceived BMI correlate was measured with the Body Silhouettes Test, BMI using height (stadiometer) and body weight, as well as body composition (bioimpedaniometer); the stages of change were measured with the Change Assessment Scale at the University of Rhode Island Short Version (URICA). Each of these variables was assessed pre-intervention and in each of the three-monthly post-intervention follow-ups. Variables and instruments are described more fully in subsequent sections.

\subsubsection{Autoperception of the body image}

Involves the perception of one's size and shape of the body. ${ }^{[9]}$ The SPBI can be studies visually which expounds how people perceive their body figure. It was evaluated the Body 
Silhouette Test, adapted by the proposed method of Stunkard and Stellard and modified by Collins, ${ }^{[14]}$ the internal consistency had a Cronbach Alpha coefficient of 0.72 according to Meneses and Moncada, ${ }^{[15]}$ containing 9 female silhouettes and 9 male silhouettes. Each one corresponds to one
IMC established from left to right on a progressive range of $17 \mathrm{~kg} / \mathrm{m}^{2}$ to $33 \mathrm{~kg} / \mathrm{m}^{2}$, the IMC was eliminated for the self-administered participants. Each student observed and indicated the figure which they identified themselves at the time of the application (not how they liked to feel).

Table 1. Educational intervention programming "Nutrition Stabilization Model-ESNUT" aimed at newly admitted university students

\begin{tabular}{|c|c|c|c|}
\hline \multicolumn{4}{|c|}{ Session } \\
\hline 1 (2h) & 2 (2h) & $3(2 h)$ & $4(2 h)$ \\
\hline $\begin{array}{l}\text { Food and } \\
\text { nutrition. } \\
\text { Pre-university } \\
\text { versus university } \\
\text { lifestyle }\end{array}$ & $\begin{array}{l}\text { Promoting good nutrition } \\
\text { Nutrition as a value. } \\
\text { Nutritional requirements. } \\
\text { Right diet } \\
\text { Reading labels of food } \\
\text { products. } \\
\text { University students' diet. }\end{array}$ & $\begin{array}{l}\text { Empowerment based } \\
\text { on the decision } \\
\text { The balance of the } \\
\text { decision: } \\
\text { Pros-Cons of the way } \\
\text { you eat versus the right } \\
\text { way. }\end{array}$ & $\begin{array}{l}\text { Moving towards action } \\
\text { Design and preparation of healthy menus. } \\
\text { Result of the decision } \\
\text { Agreement to eat a correct diet with follow-up. }\end{array}$ \\
\hline \multicolumn{4}{|c|}{ Educational strategies ${ }^{*}$} \\
\hline \multicolumn{3}{|c|}{$\begin{array}{l}\text {-Pre-organizer. } \\
\text {-Evaluation of previous knowledge. } \\
\text {-Exhibition with visual supports. } \\
\text {-Ask. } \\
\text {-Recollection and assessment of knowledge of the previous session. } \\
\text {-Group discussion. } \\
\text {-Decision making. } \\
\text {-Verbal report. } \\
\text {-Closure and knowledge assessment. }\end{array}$} & $\begin{array}{l}\text {-Design and preparation of menus with } \\
\text { demonstration, supervision and feedback of the } \\
\text { expert in the preparation of menus. } \\
\text {-Sensory reinforcement: tasting of the prepared } \\
\text { menu. } \\
\text {-Agree-Disagree with brief statements about } \\
\text { nutritional recovery and food and reflect on the } \\
\text { cost-benefit balance of healthy nutritional behavior. }\end{array}$ \\
\hline
\end{tabular}

"Morales Campos A. Estrategias didácticas para el desarrollo de competencias. 2012.ANUIES, México.

\subsubsection{Body Mass Index}

Establishes a relationship between height and weight of an individual. Identifies if a person has low weight, normal weight, overweight or obesity. ${ }^{[16]}$ Digital stadiometer model SECA 274 was used with range of 30 to $220 \mathrm{~cm}$ and a precision of $0.1 \mathrm{~cm}$ to certify the height of students under the method established by the International Society of Advancement of Kinanthropometry (ISAK). ${ }^{[17]}$ The data for the weight measurement was taken from the analysis of body composition with the body composition analizer InBody 230 .

\subsubsection{Body composition}

Subdivision of the organism into two principal components, greasy mass and mass free of grease (summary of the rest of the fibers). ${ }^{[18]}$ An evaluation was done with the body composition analizer InBody 230 for electrical bioempedance a range of 10 to $250 \mathrm{~kg}$, height of 95 to $220 \mathrm{~cm}$ and 3 to 99 years of age. Once the requirements where met and to prevent any biases (at least 4 hours of fasting, no exercise in the last 12 hours, having urinated at least 30 minutes before, no alcohol consumption 48 hours before, no diuretic intake at least 7 days before, not menstruating, no shoes or socks, or personal objects, and placement of feet and hands in the appropriate electrodes), at the conclusion of the measurements a brief explanation was given to the participants on the results of their body composition.

\subsubsection{Stages of change}

Stages that a person undergoes to achieve changes in the behavior. ${ }^{[19]}$ It was evaluated by the Evaluation Scale of Change of the University of Rhode Island Short Version (URICA), with an internal consistency of $\geq 0.61$ and $\leq 0.85$ (precontemplation ( $\alpha=0.61)$, contemplation $(\alpha=0.68)$, action $(\alpha=0.85)$ and maintenance $(\alpha=0.84)$ according to Mander et al. ${ }^{[17]}$ Of auto-application with 16 items (statements) strategically distributed, with five response options on scale Likert (1-totally disagree, 2-disagree, 3-neither agree or disagree, 4-agree, 5- totally agree), the student should carefully read each sentence and select their response accordingly and at the time of the application. Subsequently, the applicator realizes the determined summary of the instrument to obtain the stage of change. For this study the URICA questionnaire was translated into Spanish from the original version of 16 items in English and the translation corroborated by a bilingual Mexican citizen (Spanish English) with knowledge of the culture in the city the study was conducted. On the same token, a bilingual United States citizen (English Spanish) with knowledge of the Mexican cultural environment conducted a rereading of the instrument in Spanish and re-translated to the original language, correctly checking 
the translation. In addition, a pilot URICA was conducted, the pilot university students mentioned that the statements were correct, in this manner it was confirmed that URICA maintained an original sense of it statements.

\subsection{Organization and data analysis}

The data was organized and analyzed with the SPSS version 18 program. Frequencies, percentages, means and deviation standards were obtained. Study variables were correlated by means of the $\mathrm{r}$ of Pearson and $t$ of Student utilized for comparing the means and significance of $p \leq .05$.

\subsection{Legal and ethical aspects}

The investigation adhered to the General Health Law regulations of México and in accordance to Article 3 Part IV 13th, 15th and Article 36th of Chapter II of the investigation of disabled or minors, related to the informed compliance of the legal representative of the minor, ${ }^{[20]}$ and to the ethical principles of the Helsinki Declaration of the World Health Association for the medical investigation of human beings, and so the participants where volunteers, received information pertinent to the study, and advised of their right to participate or leave whenever they so desired without any type of consequences. ${ }^{[21]}$ The participants identities were not revealed, the results of the analysis used only to analyze the evolution of the nutritional state and attitude changes of the participants, as well of analysis and scientific diffusion of the effects of the ESNUT intervention.

\section{RESUlts}

\subsection{Basal nutritional status}

In the basal assessment, the experimental group (EG) showed normal nutritional status according to the Real Body Mass Index (RBMI) in 6/12 (50\%) and according to the percentage of fat mass (\% FM) only two cases $(17 \%)$ were normal. In both types of nutritional diagnoses, there was a discrepancy with the Perceived Body Mass Index (PBMI), since in this case $8 / 12(67 \%)$ had a self-perception of normal weight. The rest of the diagnoses of overweight and obesity also showed a discrepancy. Therefore, overweight (OW) diagnosed by the RBMI had 5/12 (42\%) plus 1/12 (8\%) of obesity (OB), OW by $\%$ FM had $6 / 12(50 \%)$ plus $4 / 12$ OB (33\%), these cases presented discrepancy with the students' self-perception, as 4/12 (33\%) self-identified with OW and none with obesity. The only matching case was the diagnosis of low weight between the real and the self-perceived. Regarding the CG, there was only a significant difference with the EG in the diagnosis of OB according to \% FM (EG 33\%, CG 15\%, $p \leq$ $.01)$, in this group none of the students defined themselves as obese.

Published by Sciedu Press

\subsection{Nutritional status in three monthly follow-ups}

After the educational intervention, three monthly follow-ups of the nutritional evolution of the study population were carried out. The EG through the follow-ups showed a stable prevalence with respect to the basal in the diagnosis of normal nutritional status (NS) according to BMI, however, according to the \%FM the prevalence was similar to the basal (17\%) only in the first and second post-intervention month, but remarkably increased the normal NS by the third month to $50 \%$. In the prevalence of OW, stability was also observed during the three months post-intervention with respect to the basal (around 50\%). The OB was similar to the basal in the first two months, in the third there was no case.

The self-perception of normal NS of the EG students was lower in the first month of post-intervention assessment with respect to the basal, however, in the second and third month, it increased in percentage terms showing equality with the basal. In the case of self-perception of OW, a $12 \%$ increase was observed with respect to the basal, but in the second and third months, it was similar to the basal.

Comparatively, the OB in the EG and CG showed a significant difference in the first two months of follow-up, with a higher prevalence in the EG, however, in the third monthly assessment, the prevalence behavior was similar in both groups with the advantage that in the EG the OB index decreased (see Table 2).

\subsection{Comparison of means in nutritional diagnoses}

The behavior of the means in the nutritional diagnoses of both EG and CG groups was similar ( $p \geq .05$ ), except for $\%$ FM from the basal assessment up until the second postintervention month, assessments in which the EG had the highest \%FM than the $\mathrm{CG}$, at the third month no significant difference was observed between both groups at the expense of the \%FM decreased in the EG (see Table 3).

Concordance between the Real Body Mass Index versus Perceived Body Mass Index In the students' body selfperception there was a discrete lack of concordance between the perceived BMI vs. the real BMI, the EG and the CG perceived their BMI below the real BMI, a slight increase in the concordance in the final measurement was observed in both groups compared to the basal, in the $\mathrm{CG}(8.8 \%)$ but in the EG it was more noticeable (15.7\%), apparently at the expense in the decrease of the real BMI (see Table 4).

Stages of change according to the Transtheoretical Model of Change The stages of the change were modified in the course, in the EG modifications were observed in the precontemplation in which the proportion of the basal to the final measurement decreased by 21.7 percentage points, in 
contemplation remained relatively unchanged, and the most pre-contemplation increased slightly, decreased in contemoutstanding was the increase in the proportion of students in plation and increased in preparation/action although it did preparation/action. In the CG, the proportion of students in not show statistical significance (see Table 5).

Table 2. Basal distribution and three-monthly follow-ups of nutritional status based on Perceived BMI, Real BMI and \% body fat in newly admitted university students

\begin{tabular}{|c|c|c|c|c|c|c|c|c|c|}
\hline & \multirow{3}{*}{$\begin{array}{l}\text { Diagnosis } \\
\text { Nutritional } \\
\text { Losses }\end{array}$} & \multicolumn{2}{|l|}{ Basal } & \multicolumn{2}{|c|}{ Follow-up 1} & \multicolumn{2}{|c|}{ Follow-up 2} & \multicolumn{2}{|c|}{ Follow-up 3} \\
\hline & & \multirow[t]{2}{*}{$\begin{array}{l}\text { EG } \\
s=12\end{array}$} & \multirow[t]{2}{*}{$\begin{array}{l}\text { CG } \\
s=27\end{array}$} & $\begin{array}{l}\text { EG } \\
s=12\end{array}$ & $\begin{array}{l}\text { CG } \\
s=24(3)\end{array}$ & $\begin{array}{l}\text { EG } \\
\mathrm{s}=11(1)\end{array}$ & $\begin{array}{l}\text { CG } \\
s=23(1)\end{array}$ & $\begin{array}{l}\text { EG } \\
s=10(2)\end{array}$ & $\begin{array}{l}\text { CG } \\
s=13(10)\end{array}$ \\
\hline & & & & \multicolumn{6}{|c|}{$f(\%)$} \\
\hline \multirow{4}{*}{ PBMI } & $\mathrm{BP}$ & - & - & $1(8)$ & $1(4)$ & $1(9)$ & $1(4)$ & - & $1(8)$ \\
\hline & NW & $8(67)$ & $11(41)$ & $6(50)$ & $15(63)$ & $7(64)$ & $12(52)$ & $7(70)$ & $7(54)$ \\
\hline & OW & $4(33)$ & $16(59)$ & $5(42)$ & $8(33)$ & $3(27)$ & $10(44)$ & $3(30)$ & $5(38)$ \\
\hline & OB & - & - & - & - & - & - & - & - \\
\hline \multirow{4}{*}{ RBMI } & LW & - & $1(3)$ & - & - & - & - & - & - \\
\hline & NW & $6(50)$ & $11(41)$ & $5(42)$ & $12(50)$ & $5(45)$ & $10(44)$ & $5(50)$ & $5(38)$ \\
\hline & OW & $5(42)$ & $11(41)$ & $6(50)$ & $9(38)$ & $6(55)$ & $9(39)$ & $5(50)$ & $5(38)$ \\
\hline & $\mathrm{OB}$ & $1(8)$ & $4(15)$ & $1(8)$ & $3(12)$ & - & $4(17)$ & - & $3(24)$ \\
\hline \multirow{4}{*}{$\% \mathrm{BF}$} & $\mathrm{LF}$ & - & $1(3)$ & - & $2(8)$ & - & $4(17)$ & - & $1(8)$ \\
\hline & $\mathrm{H}$ & $2(17)$ & $18(67)$ & $2(17)$ & $14(58)$ & $2(18)$ & $13(57)$ & $5(50)$ & $8(62)$ \\
\hline & OW & $6(50)$ & $4(15)$ & $6(50)$ & $3(13)$ & $5(46)$ & $2(9)$ & $3(30)$ & $2(15)$ \\
\hline & $\mathrm{OB}$ & $4(33)$ & $4(15)^{* *}$ & $4(33)$ & $5(21)^{*}$ & $4(36)$ & $4(17)^{* *}$ & $2(20)$ & $2(15)$ \\
\hline
\end{tabular}

Note. $\mathrm{BMI}=$ Body Mass Index, $\mathrm{PBMI}=$ Perceived Body Mass Index, $\% \mathrm{BF}=$ Body Fat percentage, $\mathrm{LW}=$ Low Weight, $\mathrm{NW}=\mathrm{Normal} \mathrm{Weight}, \mathrm{OW}=$ Overweight, $\mathrm{OB}=$ Obesity, $\mathrm{LF}=$ Low Fat, $\mathrm{H}=$ Healthy, $\mathrm{EG}=$ Experimental Group, $\mathrm{CG}=$ Control Group, $\mathrm{s}=$ sample, $\mathrm{f}=$ frequency, Paired Student $t$ Test. Significant differences are noted: ${ }^{*} p \leq .05{ }^{* *} p \leq .01$.

Table 3. Difference of means real BMI, perceived BMI and body fat\% of Experimental Group versus Control Group of newly admitted university students

\begin{tabular}{lllll}
\hline & RBMI & & PBMI & \% Fat \\
\cline { 2 - 2 } \cline { 5 - 5 } & EG vs. CG & EG vs. CG & EG vs. CG \\
\hline Basal & $24.7 \pm 3.2$ vs. $25.8 \pm 3.9$ & & $23.1 \pm 1.8$ vs. $24.0 \pm 2.6$ & $32.6 \pm 5.2$ vs. $22.6 \pm 10.4^{* *}$ \\
FU1 & $24.8 \pm 3.3$ vs. $25.6 \pm 3.9$ & & $23.1 \pm 3.0$ vs. $23.2 \pm 2.7$ & $32.9 \pm 4.8$ vs. $22.1 \pm 11.9^{* *}$ \\
FU2 & $24.3 \pm 2.7$ vs. $25.5 \pm 4.0$ & & $23.1 \pm 3.0$ vs. $23.7 \pm 2.8$ & $33.4 \pm 5.0$ vs. $20.7 \pm 11.2^{* *}$ \\
FU3 & $24.2 \pm 2.7$ vs. $26.6 \pm 4.2$ & & $23.2 \pm 2.8$ vs. $23.7 \pm 3.0$ & $28.4 \pm 8.5$ vs. $23.2 \pm 10.8$ \\
\hline
\end{tabular}

Note. FU1 = Follow-up one FU2 = Follow-up two FU3 = Follow-up three. RBMI = Real Body Mass Index, PBMI = Perceived Body Mass Index. EG $=$ Experimental Group $\mathrm{CG}=$ Control Group. Student $T$ test for independent samples. ${ }^{*} p \leq .05^{* *} p \leq .01$

Table 4. Level of concordance between the Real Body Mass Index versus Perceived Body Mass Index in newly admitted university students

\begin{tabular}{|c|c|c|c|c|c|c|c|c|}
\hline \multirow{3}{*}{$\begin{array}{l}\text { Measurement } \\
\text { Group }\end{array}$} & \multicolumn{2}{|l|}{ Basal } & \multicolumn{2}{|c|}{ Follow-up 1} & \multicolumn{2}{|c|}{ Follow-up 2} & \multicolumn{2}{|c|}{ Follow-up 3} \\
\hline & EG & CG & EG & CG & EG & CG & EG & CG \\
\hline & & & \multicolumn{6}{|c|}{ Mean (SD) } \\
\hline RBMI & $24.7 \pm 3.2$ & $25.8 \pm 3.9$ & $24.8 \pm 3.3$ & $25.6 \pm 3.9$ & $24.3 \pm 2.7$ & $25.5 \pm 4.0$ & $24.2 \pm 2.7$ & $26.6 \pm 4.2$ \\
\hline PBMI & $23.1 \pm 1.8$ & $24.0 \pm 2.6$ & $23.1 \pm 3.0$ & $23.7 \pm 2.8$ & $23.1 \pm 3.0$ & $23.7 \pm 2.8$ & $23.2 \pm 2.8$ & $23.7 \pm 3.0$ \\
\hline Concordance \% & 58.9 & 59.2 & 66.5 & 67.2 & 59.0 & 67.3 & 74.6 & 68.0 \\
\hline
\end{tabular}

Note. RBMI = Real Body Mass Index. PBMI = Perceived Body Mass Index. EG = Experimental Group. CG = Control Group. SD = Standard Deviation. To obtain the concordance, Pearson's r correlation test was used.

Table 5. Stages of change according to the transtheoretical model of health behavior change of newly admitted university students

\begin{tabular}{|c|c|c|c|c|c|c|}
\hline \multirow{3}{*}{ Stage } & \multicolumn{2}{|c|}{ Precontemplation } & \multicolumn{2}{|c|}{ Contemplation } & \multicolumn{2}{|c|}{ Preparation/Action } \\
\hline & Basal & Final & Basal & Final & Basal & Final \\
\hline & \multicolumn{6}{|c|}{ f (\%) } \\
\hline EG & $5(41.7)$ & $2(20.0)$ & $7(58.3)$ & $6(60.0)$ & $0(0.0)$ & $2(20.0)$ \\
\hline CG & 7 (25.9) & $4(30.8)$ & $17(63.0)$ & $6(46.2)$ & $3(11.1)$ & $3(23.1)$ \\
\hline
\end{tabular}

Note. $\mathrm{EG}=$ Experimental Group $\mathrm{CG}=$ Control Group. Student $\mathrm{t}$ test for related samples. ${ }^{*} p \leq .05$ 


\section{Discussion}

\subsection{Nutritional condition}

In the EG of this study, the basal \%FM and over two followups it increased between $0.3 \%$ to $0.5 \%$, a result consistent with a follow-up study of Mexican students in the first six months at the university with three \%FM assessments, which increased significantly in the three follow-up cut points in both women and men. ${ }^{[4]}$ However, in our study, the \%FM indicator of the EG was reduced by 5 percentage points towards the third month of assessment. On the other hand, from the start the \%FM of the CG was lower by approximately 10 percentage points with respect to the EG and over two follow-ups it still decreased the fat composition between 0.5 and $1.4 \%$, a situation that reversed as it was towards the third month of follow-up that an increase of 2.5 percentage points was observed. The assessment of the changes in BMI were similar to the behavior of \%FM in the CG and to the study of university students assessed during six months in which the BMI increased significantly between the first and second cut in both genders, ${ }^{[4]}$ not in the EG of our study in which this index decreased from the second post-intervention month. It is significant that the manner of food consumption of new university students contributes to changes in nutritional status, mostly in overweight and obesity. Among the nutritional changes in the first semester of the university we can also see weight loss evidenced in BMI and/or in \% FM, in this study there were cases of low weight in the CG, a proportion that increased between the basal measurement and the second follow-up, not thus in the EG, which could be attributed in the intervention used in our study whose focus is towards nutritional stabilization based on any nutritional diagnosis and not only on weight reduction and \%FM.

\subsection{Self-perception of body image}

In the case of normal weight, the EG had a self-perception of normal weight in more than half of the cases $(67 \%)$ versus the real $50 \%$, between $30 \%$ to $44 \%$ had a self-perception in OW and the real was greater with 20 percentage points, a marked difference between self-perception and the real nutritional status is observed. While the $\mathrm{CG}$ with a tendency to overestimate has a self-perception of overweight in more than a third of the cases when in reality less than $10 \%$ had OW. We want to draw attention to the possibility of dissatisfaction with body image, especially in women, although it was not the object of study of this paper, the discrepancy between body self-perception with real BMI has been reported in transverse and longitudinal studies and additionally the lack of satisfaction with the appearance of the body itself that they see as distant from the ideal figure in adolescents, young adults or even adulthood, a more pronounced situation in women, and surprisingly it was higher in healthy women compared to their peers with cystic fibrosis, all this is related to low self-esteem that can lead to unhealthy nutritional and physical activity behaviors. ${ }^{[22,23]}$

The EG and CG started with a concordance level between body self-perception-real nutritional status near to $60 \%$, the EG increased the concordance level with 15.7 percentage points $(58.8 \%-76.4 \%)$, the CG also slightly increased the concordance level although only in $8.8 \%$ (59.2\%-68.0\%), relatively higher proportions compared to a study carried out in Spain in 2016 where they also used Stunkard's silhouettes to identify the body's self-perception of the participants in which they made a correlation with which a concordance resulted between perceived BMI and average real BMI of 44.3\%.[24] Likewise, in a Mexican study it was observed that the majority of adolescents overestimated their weight since less than half (43\%) actually showed it, $50 \%$ of the participants tended to get right their real BMI. ${ }^{[9]}$

Factors to take into consideration for the success of individual and collective nutritional interventions.

\subsection{Stages of behavior change}

In this study, a quarter of the population (25.9\%) and two thirds $(63.0 \%)$ of the $\mathrm{CG}$ were in precontemplation and contemplation respectively and $11.1 \%$ were in preparation/action, while none of the EG students were in preparation/action, they were only in the precontemplation (41.7\%) and contemplation (58.3\%) stage, in a study with Brazilian adolescents it was similarly reported that half were in precontemplation, but differed in the preparation/action stage with a higher index (22\%), these participants showed greater changes reduced sugary drinks and increased intake of fruits and beans as suggested. ${ }^{[11]}$

This paper shows a greater advance towards the preparation/action stage in the EG having progressed from $0 \%$ to $20 \%$ at the end, unlike the CG that started with $11 \%$ at this stage and ended with $23 \%$, these results agree with those of an article review published in 2014 in the United Kingdom, which assessed the intervention implemented for the participants to improve their lifestyle and their transit through the stages of change according to the transtheoretical model, it was observed that the intervention group progressed more $(32.5 \%)$ towards the stage of action than the participants of the control group $(25.8 \%){ }^{[25]}$

\subsection{Educational intervention}

The ESNUT intervention is based on the fundamentals of the transtheoretical model of change, the TMC has been applied to groups to control smoking, alcoholism, physical activity and the ingesting of healthy diets ${ }^{[11]}$ which allows applying flexible teaching strategies adapted to each stage aware of the 
balance of the decision, and the work and group discussion between peers, as well as the establishment of a behavior agreement for the selection, preparation, and intake of a correct diet, the results shown in the body composition in a more precise way in the participants, support the achievements of the EG students. On the contrary, when there is no theoretical reference, it is difficult to define the contribution to the success or failure of the intervention, as stated by Pember and Knowlden (2017), the limited success of educational interventions in the university context can be the result of lack of evidence and theory-based design. ${ }^{[26]}$

\section{Conclusions}

The participants of the EG evolved through the follow-ups and it was demonstrated that the applied nutritional educational intervention produced the expected results regarding the transition from the precontemplation stage to the contemplation stage, as well as from the contemplation stage to the preparation/action stage. The identification of the stage of change was an advantage at the time of feedback in the follow-ups since it allowed motivating the participant according to the stage in which they were, this transit had its correlation in the decrease of fat mass towards normal limits, the OW/OB to a great extent, were able to be normalized to the healthy and the level of concordance between BMI self-perception and real BMI was increased. On the other hand, the CG made little progress due to relapses to predecessor stages and it showed in an increase in body fat of those who were underweight or healthy and the students in OW/OB remained unchanged, as well as the concordance between perceived BMI and real BMI with little progress. However, both groups tended to underestimate the perceived BMI versus real BMI. In spite of which it is not conclusive since the follow-up does not last for at least six months to demonstrate the establishment of a healthy habit according to the theory of change.

\subsection{Limitations}

Difficulty in recruiting the sample, especially the EG and the permanence of the CG in the study during the follow-up, despite the communication strategies by electronic means at the participants' proposal.

\subsection{Recommendations}

Increase the sample and follow-up at least to six months post-intervention to assess the establishment of correct eating habits and include the analysis of satisfaction with body self-image and its influence on eating behaviors.

Suggest to the university authorities to consider the positive results of this study to implement the ESNUT intervention starting with the newly admitted students to the institution.

\section{ACKnOWledgements}

Fondo de Apoyo a la Investigación-Universidad Autónoma de San Luis Potosí. Proyecto: Diagnóstico nutricional por método clínico y por bioimpedancia. FAI 2007-C07-FAI-II56.92.

FOMIX-2013 Consejo Potosino de Ciencia y Tecnología (COPOCYT). FMSLP-2013-C02-208475. Proyecto "Evaluación del impacto de los programas de apoyo alimentario en el estado de nutrición de la población infantil en San Luis Potosî"

Mr. Gerardo Montemayor who supported the translation of the first section.

\section{CONFlicts of InTERest Disclosure}

The authors declare that there is no conflict of interest.

\section{REFERENCES}

[1] Gaete V. Adolescent psychosocial development. Rev Chil Pediatr. 2015; 86(6): 436-443. PMid:26342392 https://doi.org/10.1016/j.rchipe.2015.07.005

[2] Instituto Nacional de Estadística y Geografía [en línea]. México: INEGI; 2019. Available from: https: //www.inegi.org.mx/sistemas/olap/consulta/general_ ver4/MDXQueryDatos_Colores.asp?proy=enoe_pe_ed15_pt

[3] The Organization for Economic Co-operation and Development. México: OECD; 2017. Available from: oecd.org/education/s kills-beyond-school/EAG2017CN-Mexico-Spanish.pdf

[4] Franco K, Valdés EH. Food consumption frequency, Body Mass Index and Body Mass percentage among university students: a longitudinal study . Rev. Cienc. UAT [On line]. 2013; 7(2): 18-22. https://doi.org/10.29059/cienciauat.v7i2.12
[5] Fernández Torres A. Estudio del efecto de una intervención nutricional colectiva sobre la alimentación de los universitarios. Universidad de Córdoba. 2016. http://hdl . handle. net/10396/13372

[6] Gatica R, Yunge W, Quintana C, et al. Association between sedentarism and bad dietary habits among nutrition students. ALANArchivos Latinoamericanos de Nutrición. 2017; 67(2): 122-129.

[7] Aguirre LH, Reyes S, Ramos BS, et al. Relationship between satisfaction and perceived body image, body composition and physical exercise in gym users . Rev Iberoam de Psicol del Ejerc y Dep. 2017; 12(1): 149-156.

[8] Axpe I, Infante BG, Fernández ZA. Is it possible to enhance the physical self-concept of university students' using a cognitive intervention? Acción Psicológica. 2015; 12(1): 23-34. https ://doi.or g/10.5944/ap.12.1.11864

[9] Sámano R, Rodríguez VAL, Sánchez JB, et al. Body image satis- 
faction in mexican adolescents and adults and its relation with body selfperception and real Body Mass Index. Nutr Hosp. 2015; 31 (2): 1082-1088.

[10] Jiménez CR, Moreno NB, Leyton RM, et al. Motivación y estadios de cambio para el ejercicio físico en adolescentes. Rev Lat Psicol. 2015; 47: 196-204. https://doi.org/10.1016/j.rlp.2014.11.001

[11] Barbosa CD, Nalin SBS, de Veiga GV, et al. Readiness for behavioral change and variation in food consumption among adolescents from a school-based Community trial in Duque de Caxias, RJ. Rev Bras Epidemiol. 2015; 18(3): 655-665. PMid:26247189 https://doi.org/10.1590/1980-5497201500030011

[12] Reyes HJ, Gallegos MJ. Nutrición y Salud: Apoyo y Orientación para Proveedores de Salud. 1 ${ }^{\text {a }}$ edición. México: Ed. UASLP; 2015.

[13] Sánchez TJ. Educación para la salud: una introducción. México: Manual Moderno; 2013

[14] Collins ME. Body figure perceptions and preferences among preadolescent children. International Journal of Eating Disorders. 1991; 10: 199-108. https://doi.org/10.1002/1098-108X (199103)10: 2<199: :AID-EAT2260100209>3.0.CD;2-D

[15] Meneses M, Moncada J. Imagen corporal percibida e imagen corporal deseada en estudiantes universitarios costarricenses. Revista Iberoamericana de Psicología del Ejercicio y el Deporte. 2008; 3(1): 13-30.

[16] Gil HA. Tratado de Nutrición: Nutrición humana en el estado de salud. 2a ed. España: Editorial Médica Panamericana; 2010.

[17] Mander J, Wittorf A, Teufel M, et al. Patients with depression, somatoform disorders, and eating disorders on the stages of change: validation of a short version of the URICA. Psychotherapy. 2012; 49(4): 519-27. PMid:23088312 https://doi .org/10.1037/a0029563

[18] Suverza A, Haua K. El ABCD de la evaluación del estado de nutrición. México: McGraw Hill; 2010.
[19] Esparza VOA, et al. Cuestionario de ejercicio basado en el modelo transteórico de la conducta en una muestra mexicana. Enseñanza e Investigación en Psicología. 2013; 18(1): 125-141.

[20] Ley General de Salud. Nueva Ley publicada en el Diario Oficial de la Federación el 7 de febrero de 1984. Texto vigente. Últimas reformas publicadas en el Diario Oficial de la Federación el 24 de febrero del. 2005.

[21] Asociación Médica Mundial. 41ª Asamblea Médica Mundial Hong Kong, septiembre de 1989.

[22] Serpa SJC, et al. Relationship between physical activity, body composition and body image in university students. SPORT TK: Revista Euroamericana de Ciencias del Deporte, julio. 2017; 6(2): 39-48.

[23] Abbott J, et al. Perceived body image and eating behavior in young adults with cystic fibrosis and their healthy peers. Journal of Behavioral Medicine. 2000; 23(6): 501-517. PMid:11199084 https : //doi.org/10.1023/A : 1005532602084

[24] Chacón R, Zurita F, Castro M, et al. Research of the applicability of exergames for the improvement of obesity index and body image in school children. RIPED. 2016; 11(1): 97-105.

[25] Mastellos N, Gunn LH, Felix LM, et al. Transtheoretical model stages of change for dietary and physical exercise modification in weight loss management for overweight and obese adults. Cochrane Database Syst Rev. 2014; 2(2): 5-87. PMid:24500864 https: //doi.org/10.1002/14651858.CD008066.pub3

[26] Rubio CE, Zárate DNE, Salazar SDY, et al. Efecto de las intervenciones educativas enfocadas en la modificación de hábitos alimenticios en estudiantes universitarios. Debates en Evaluación y Currículum/Congreso Internacional de Educación: Evaluación 2018. Available from: http://postgradoeducacionuatx.org/pdf 20 18/C015.pdf 